Journal of Applied Pharmaceutical Science Vol. 5 (08), pp. 046-053, August, 2015

Available online at http://www.japsonline.com

DOI: $10.7324 /$ JAPS.2015.50808

ISSN 2231-3354 (cc) BY-NC-SA

\title{
Evaluation of in-vivo antiarthritic potential of methanolic extract of Costus speciosus rhizome
}

\author{
Chandra Kala ${ }^{1}$, Syed Salman $\mathrm{Ali}^{2 *}$, Mohd. Abid ${ }^{2}$, U S Sharma ${ }^{3}$, Najam Ali Khan ${ }^{2}$ \\ ${ }^{1}$ Department of Pharmaceutical Technology, MIET, N.H. 58, Delhi-Roorkee Highway, Baghpat Road Bypass Crossing,Meerut-250005, UP, India. \\ ${ }^{2}$ School of Pharmaceutical Sciences, IFTM University, Lodhipur rajput, Delhi road (NH-24), Moradabad - 244102, Uttar Pradesh, India. \\ ${ }^{3}$ Sir Madanlal Institute of Pharmacy, Alampur Hauz, Agra Road, Etawah -206001 (UP), India.
}

\begin{tabular}{|c|c|}
\hline ARTICLE INFO & ABSTRACT \\
\hline $\begin{array}{l}\text { Article history: } \\
\text { Received on: } 24 / 04 / 2015 \\
\text { Revised on: } 16 / 05 / 2015 \\
\text { Accepted on: } 19 / 06 / 2015 \\
\text { Available online: } 28 / 08 / 2015\end{array}$ & $\begin{array}{l}\text { Objective: To evaluate anti-arthritic potential of methanolic extract of rhizome of Costus speciosus Koen. } \\
\text { Methods: The powdered drug was extracted with } 80 \% \text { methanol. The crude extract was subjected to } \\
\text { phytochemical investigation and was evaluated for its anti-arthritic potential by freund's complete adjuvant } \\
\text { induced arthritis model in adult wistar albino rats. Determination of different parameters like arthritic score, } \\
\text { arthritic index, paw thickness, body weight, and pain, altered liver enzymes and biochemical estimation like, }\end{array}$ \\
\hline $\begin{array}{l}\text { Key words: } \\
\text { Costus speciosus, Freund's } \\
\text { complete adjuvant, } \\
\text { Rheumatoid arthritis, } \\
\text { biochemical estimation, } \\
\text { radiological examination. }\end{array}$ & $\begin{array}{l}\text { tarsal joints was performed. Statistical analysis was performed using one way ANOVA followed by Dunnet's test } \\
\text { at different p-values. Results: Phytochemical study revealed the presence of flavonoids, phenolic compound, } \\
\text { saponins and carbohydrates. For different parameter mentioned above, anti-arthritic activity shown by } \\
\text { prophylactic high dose test extract }(200 \mathrm{mg} / \mathrm{kg}) \text { was as potent as standard drug Indomethacin }(10 \mathrm{mg} / \mathrm{kg}) \text {. The } \\
\text { effect of Prophylactic low dose extract }(100 \mathrm{mg} / \mathrm{kg}) \text { and therapeutic high dose extract }(200 \mathrm{mg} / \mathrm{kg}) \text { was less than } \\
\text { that of Indomethacin }(10 \mathrm{mg} / \mathrm{kg}) \text {. Furthermore, Therapeutic low dose extract }(100 \mathrm{mg} / \mathrm{kg}) \text { was not effective. } \\
\text { Conclusions: The obtained results indicate that Costus speciosus rhizome extract possess significant anti-arthrtic } \\
\text { potential. }\end{array}$ \\
\hline
\end{tabular}

\section{INTRODUCTION}

Currently, there is extensive utilization of higher plant as a major source of therapeutic agent throughout the world, as they contain many phytoconstituents of pharmacological benefits (Rani et al., 2012).Secondary plant metabolites previously with unknown pharmacological activities have been investigated as a source of medicinal agents (Momin et al., 2014). India has officially recognized list of 45,000 plant species among which list of 7500 plant species were suggested for their medicinal uses (Srivastava et al., 2011). The World Health Organization (WHO) estimates that $80 \%$ of the world population presently uses herbal medicine for some aspect of primary health care. Herbal medicine is a major component in all indigenous people's traditional medicine and a common element in Ayurvedic, homeopathic, naturopathic, traditional oriental. WHO notes that of 119 plant-derived pharmaceutical medicines, about $74 \%$ are

\footnotetext{
*Corresponding Author

Email: salmanali.ali32@gmail.com
}

used in modern medicine in ways that correlated directly with their traditional uses. Major pharmaceutical companies are conducting extensive research on plant materials gathered from the rain forests and other places for their potential medicinal value (Oristoki and Oguntibejw, 2010).

Rheumatoid arthritis (RA) is common auto-immune inflammatory arthritis, with prevalence of $0.5-1 \%$ occurring throughout the world and ethnic group with reduction in expected lifespan by 8-15 years (Boon, 2006, Srivastava et al., 2012). NSAIDS, DMARDS and combination of both are preferred medication for present scenario. But, adverse effect attributable to use of Disease modifying antirheumatic drugs (DMARDs) and Non-steroidal anti-inflammatory drugs (NSAIDS), particularly in aged patient, has dragged their attention for alternative medication (Bhangle and Acharya, 2014)

Costus speciosus is herbaceous plant belonging to family Costaceae (Chang et al., 2012). Costus speciosus has been scientifically possesses anti-inflammatory activity, anti-nociceptive activity, anti-diabetic activity, anti-oxidant activity, anti-microbial, normoglycemic, hypoglycaemic and oestrogenic activity. 
Traditionally, the rhizome extract of Costus speciosus is used in rheumatism and antiarthritic activity of aerial part of Costus speciosus is also reported. Anti-arthritic effect of rhizome of Costus speciosus are still to be explored. Therefore, the present research work has been undertaken to evaluate the anti-arthritic effect of rhizome extract of Costus speciosus.

\section{MATERIALS AND METHODS}

\section{Collection and identification of plant material}

The Semi-dried rhizome of Costus speciosus were identified, purchased and authenticated from VHCA herbals, Karnal, Haryana, India.

\section{Extraction of rhizome of Costus speciosus rhizome}

The dried powder of Costus speciosus koen rhizome was extracted using soxhlet apparatus with chloroform for $60 \mathrm{~min}$ to remove the wax, oil, chlorophyll, and non-polar phenolic compounds. Then, the residue was extracted with $80 \%$ methanol solution for $12 \mathrm{hrs}$ at temperature $70-75^{\circ} \mathrm{C}$. The extract was concentrated under vacuum using rotary vacuum evaporator (Flash, Bucchi type), dried and weighed (Chang et al., 2012).

\section{Experimental Animals}

All the experiments were performed using male wistar albino rats weighing between 150-200 gm of either sex. Animals were procured from Central Animal House, MIET, Meerut. Animals were approved by Institutional Animal Ethic Committee (IAEC) of MIET, Meerut.

Approval number CPCSEA No. 711/02/a/CPCSEA was given for this work. Animals were housed in polypropylene cages. Standard conditions of temperature $25 \pm 2{ }^{\circ} \mathrm{C}$ and relative humidity $60-70 \%$ was maintained. The animals were fed with a standard diet and water adlibitum. Six animals were used in each group.

\section{Drugs and Chemicals}

\section{Drugs}

Indocap (Indomethacin) was purchased from local medical store of Meerut.

\section{Chemicals}

Freund's complete adjuvant was purchased from Sigma Aldrich. EDTA, was purchased from Rapid Diagnostic pvt. Ltd. Delhi, Sodium chloride, Zinc sulphate, barium chloride, Sulphuric acid, 5, 5-dithiobis-2-nitrobenzoic acid (DTNB), Acetyl thiocholine iodide, Trichloroacetic acid (TCA), Thiobarbituric acid (TBA), Sodium dihydrogen phosphate, disodium hydrogen phosphate, Petroleum ether, Ethanol, Chloroform, Methanol were purchased from Central Drug House Laboratory (CDH). Laboratory reagent grade chemicals were used in the study.

\section{Phytochemical screening}

Test for Flavanoids: Zinc hydrochloride test

Test for Saponins: Foam test

Test for Alkaloids: Dragendorff's Test

Test for Steroids and Sterols: Salkowski Test

Test for Amino Acids: Ninhydrin Test

Test for Carbohydrates: Molisch's Test (Treas and Evans, 2002)

Test for Tannins (Khandelwal, 2008): Extract $+5 \%$ ferric chloride solution

Test for phenolic compounds (Al-Mailiki, 2011): Ferric chloride test

\section{Acute oral toxicity Study $\left(\mathbf{L D}_{\mathbf{5 0}}\right)$ :}

Animals were fasted prior to test drug administration. Following the period of fasting animals was weighed and then the test substance administered in a single dose of $2000 \mathrm{mg} / \mathrm{kg}$ to animals by oral gavage. After the test drug administration, food was withheld for next 3-4 hours. Following administration, animals were closely observed for next 4 hours to see any clinical symptom, any change in behavior or mortality. After 6 hours of test administration the animals weighed again. A careful clinical examination was made once in each day for next 14 days (OECD 4/26, 2006)

\section{Freund's complete adjuvant induced arthritis Induction of arthritis}

$0.1 \mathrm{ml}$ of Freund's complete adjuvant (FCA) (composed of $1 \mathrm{mg} / \mathrm{ml}$ heat killed Mycobacterium tuberculosis, mineral oil and mannide monooleate) was injected in sub-plantar region of left hind paw of rats (Anderson, 2009).

\section{Treatment Protocol}

Rats were divided into seven groups. Group I served as control group and received $0.5 \%$ of CMC. Group II served as arthritic control and received $0.5 \% \mathrm{CMC}$ and FCA. Group III served as standard group and received Indomethacin $(10 \mathrm{mg} / \mathrm{ml}$, p.o). Group IV and group V served as test group and received prophylactic low dose of test extract $(100 \mathrm{mg} / \mathrm{kg})$ and prophylactic high dose of test extract $(200 \mathrm{mg} / \mathrm{kg})$, respectively. Group VI and group VII served as test group and received therapeutic low dose of test extract $(100 \mathrm{mg} / \mathrm{kg})$ and therapeutic high dose of test extract (200 mg/kg). All the group except group I, received $0.1 \mathrm{ml}$ of FCA along with treatments. All the treatments of group I and V were started at day 0 and continued till day 28. Treatments of group VI and VII were started at day 14 and continued till day 28.

\section{Determination of antiarthritic potential Arthritic Score}

Animals were scored by observing their left hind paw from day 0 to day 28. Each animal was scored depending upon the severity of edema of paw. Score 0 indicated no arthritis. Score1 indicated redness or swelling of one toe/finger joint. Score 2 indicated redness and swelling of more than one toe/finger joint. 
Score 3 indicated ankle and tarsal/metatarsal joint involvement. Score 4 indicated entire paw redness and swelling (Ramprasath, 2006).

\section{Arthritic index}

Arthritic index was calculated by sum of arthritic score (Vogel and Vogel, 2010).

\section{Pain}

Compression test

The digital vernier caliper measured the thickness of inflamed paw. The paw was compressed by rotating the screw of digital vernier caliper till pain was elicited as indicated by squeaking or leg withdrawal. The distance moved by the screw gauze was recorded (Sehgal and Kumar, 2005).

\section{Inflammation}

Measurement of paw volume by plethysmometer

Paw volume was measured up to a fixed mark on the tibio tarsal joint at $0,7,14,21$ and 28 day using a manual plethysmometer. Edema volume was calculated at each time interval as the difference from paw volume at 0 day (Gaspar,2007).

\section{Measurement of paw thickness}

Paw thickness was measured by digital vernier caliper.

Body weight

Body weight was determined by digital weighing balance.

\section{Determination of liver enzyme}

Liver enzymes were determined by using commercial kit by autoanalyser.

\section{Biochemical assay}

\section{Nitric Oxide estimation}

About $1 \mathrm{ml}$ of blood was drawn from the animals of each group by retro orbital puncture. The blood samples were centrifuged at $3000 \mathrm{rpm}$ for about $10 \mathrm{~min}$ to collect the serum. Serum samples were taken in test tubes and treated with Griess reagent $\quad(1 \% \quad$ sulphanilamide, $0.1 \%$ naphthylethylenediamine dihydrochloride and $2.5 \%$ hydrochloric acid).
The colorimetric reaction was allowed to proceed for $10 \mathrm{~min}$ at room temperature, and optical density was measured at $550 \mathrm{~nm}$ using a spectrophotometer. The concentrations of nitrite were calculated from a standard curve established with serial dilutions of sodium nitrite (Menaka et al., 2009.)

\section{Plasma TNF- $\alpha$ estimation}

As per the instruction of kit (Plasma TNF- $\alpha$ level, Sigma Aldrich, India ).

\section{Radiological estimation}

Radiographic evaluation was performed by Kent diagnostic centre, Meerut.

\section{Histopathological assessment}

All the animals were sacrificed at the end of the study and tibiotarsal joints of rats were removed and were sent to Deptt. of pathology, Swami Vivekanand Subharti University, Meerut for evaluation.

\section{RESULTS}

\section{Phytochemical screening}

Phytochemical test performed to determine the phytoconstituents revealed the presence of phenolic compound, flavonoids, steroidal compounds, saponins and carbohydrates.

\section{Acute oral toxicity}

No sign of mortality was found at the dose of 2000 $\mathrm{mg} / \mathrm{kg}$. Hence two doses were selected $100 \mathrm{mg} / \mathrm{kg}$ as lower dose and $200 \mathrm{mg} / \mathrm{kg}$ as higher dose to check the effectiveness of test drug.

\section{Anti-arthritic activity Arthritic score}

The mean arthritic score in FCA induced arthritis and other treatment group was progressive till day 7 . Treatment with Indomethacin $(10 \mathrm{mg} / \mathrm{kg}$, p.o $)$ reduced the arthritic score significantly from Day 7 to Day 28. Similarly, in PHDE (200 $\mathrm{mg} / \mathrm{kg}$, p.o) there is significant reduction in arthritic score from Day 14 to day 28. In PLDE (100 mg/kg, p.o) reduction in mean score is less significant than Indomethacin and PHDE. In TLDE $(100 \mathrm{mg} / \mathrm{kg}$, p.o) and THDE $(200 \mathrm{mg} / \mathrm{kg}$, p.o) reduction in mean arthritic score is less significant as compared to all groups. The results are shown in Table 1.

Table 1: Effect of Costus speciosus Koen extract on arthritic score.

\begin{tabular}{|c|c|c|c|c|c|}
\hline \multirow[t]{2}{*}{ Treatment } & \multicolumn{5}{|c|}{ Arthritic score } \\
\hline & Day 0 & Day 7 & Day 14 & Day 21 & Day 28 \\
\hline Control (0.5 \% CMC) & 0 & 0 & 0 & 0 & 0 \\
\hline Arthritic control & $1.67 \pm 0.21$ & $3.67 \pm 0.21$ & $3.67 \pm 0.21$ & $3.83 \pm 1.66$ & $3.50 \pm 0.22$ \\
\hline Indomethacin $(10 \mathrm{mg} / \mathrm{kg})$ & $1.83 \pm 0.17$ & $2.16 \pm 0.17 * * *$ & $1.67 \pm 0.21 * * *$ & $1.34 \pm 0.21 * * *$ & $0.83 \pm 0.30 * * *$ \\
\hline PLDE (100 mg/kg) & $1.85 \pm 0.16$ & $3.34 \pm 0.33$ & $2.67 \pm 0.21$ & $2.67 \pm 0.21 * *$ & $2.17 \pm 0.30 * *$ \\
\hline PHDE (200 mg/kg) & $1.80 \pm 0.16$ & $2.84 \pm 0.30$ & $2.33 \pm 0.21$ & $1.83 \pm 0.30 * * *$ & $1 \pm 0.25^{* * * *}$ \\
\hline TLDE (100 mg/kg) & $1.84 \pm 0.17$ & $3.83 \pm 0.16$ & $3.67 \pm 0.210$ & $3 \pm 0.25^{*}$ & $2.17 \pm 0.17 * *$ \\
\hline THDE (200 mg/kg) & $2 \pm 0$ & $3.66 \pm 0.21$ & $3.83 \pm 0.166$ & $2.67 \pm 0.210^{* * *}$ & $1.67 \pm 0.210^{* * * *}$ \\
\hline
\end{tabular}




\section{Arthritic index}

Arthritic index was found to be maximum in arthritic control group as compared to other treatment group. It was found to be 22 on day 7 and 21 on day 28 reflecting that there is no recovery from inflammation. Whereas in other treatment group arthritic index kept on decreasing weekly reflecting the best results in group receiving indomethacin $(10 \mathrm{mg} / \mathrm{kg}$, p.o) with arthritic index of 13 on day 7 and 5 on day 28 and in PHDE (200 $\mathrm{mg} / \mathrm{kg}$, p.o) arthritic index was found to be 17 on day 7 and decreased to 6 on day 28. The results revealed the protective effect of Indomethacin and PHDE (200 mg/kg). Reduction in arthritic index was also seen in PLDE (100 mg/kg) and THDE $(200 \mathrm{mg} / \mathrm{kg})$ but it was less significant.

\section{Compression pain test}

The effect of PHDE (200 mg/kg BW) was comparable to standard indomethacin, since, in both of these groups distance travelled $(\mathrm{mm})$ by rotating screw gauze was maximum, among all other treatment groups.

In PHDE (200 mg/kg BW) group animals the pain threshold was significantly increased in comparison to animals in PLDE (100 mg/kg BW) group. In TLDE (100 mg/kg BW) and THDE (200 mg/kg BW) there were no relief from pain till second week but as soon as treatment was started pain threshold was increased but not as significant as of standard group. The results are shown in Table 2.

\section{Inflammation}

\section{Measurement of paw volume by digital plethysmometer}

Animals in treatment groups, Indomethacin $(10 \mathrm{mg} / \mathrm{kg}$ BW) and PHDE (200 mg/kg BW) showed least volume of mercury displaced indicating highly significant reduction in paw edema when compared to arthritic control group. In therapeutic dose treatment groups, animals of TLDE (100 mg/kg BW) and THDE (200 mg/kg BW) volume of mercury displaced increased till two weeks. Since, the treatment started after two weeks of induction of arthritis. The results are shown in Table 3.

Percent inhibition of joint inflammation is maximum in group receiving Indomethacin $(10 \mathrm{mg} / \mathrm{kg}$ BW) i.e. $55.63 \%$ followed by PHDE $(200 \mathrm{mg} / \mathrm{kg}$ ) with $51.1 \%$ of inhibition. Percent inhibition of PHDE (200 $\mathrm{mg} / \mathrm{kg})$ was followed by THDE (200 $\mathrm{mg} / \mathrm{kg}$ ) and PLDE (100 mg/kg) with $26.35 \%$ and $21.24 \%$ respectively. And, in TLDE $(100 \mathrm{mg} / \mathrm{kg})$ percent inhibition of inflammation was lowest $14.62 \%$.

\section{Average change in paw thickness (mm)}

Paw thickness was maximum in animals of arthritic group indicating highest inflammation. Paw thickness of animals in standard group (Indomethacin $10 \mathrm{mg} / \mathrm{kg} \mathrm{BW}$ ) decreased significantly weekly showing highly significant anti-inflammatory effect. Animals in PHDE (200 mg/kg BW) group have comparable efficacy to standard, in reducing paw thickness. Treatment of animals with PLDE (100 mg/kg BW) also reduced paw thickness but less significantly. THDE (200 mg/kg BW) and TLDE (100 $\mathrm{mg} / \mathrm{kg} \mathrm{BW}$ ) also reduced paw thickness but in later stage of the study, since, the treatment was started at 14 day after the induction of arthritis. The results are shown in table 4.

\section{Body weight}

Body weights of animals of standard group receiving Indomethacin (10 mg/kg BW) and PHDE (200 mg/kg BW) were increased significantly. In PLDE (100 mg/kg BW) increase in body weight was less significant. However, in TLDE $(100 \mathrm{mg} / \mathrm{kg}$ BW) and THDE (200 mg/kg BW) there was increase in body weights as treatment started but it was not significant. Results are shown in table 5 .

Table 2: Effect of Costus speciosus Koen extract on compression pain test.

\begin{tabular}{|c|c|c|c|c|c|}
\hline \multirow[t]{2}{*}{ Treatment } & \multicolumn{5}{|c|}{ Compression pain test } \\
\hline & Day 1 & Day 7 & Day 14 & Day 21 & Day 28 \\
\hline Control (0.5 \% CMC) & $0.42 \pm 0.013$ & $0.42 \pm 0.012$ & $0.43 \pm 0.01$ & $0.43 \pm 0.012$ & $0.43 \pm 0.01$ \\
\hline Arthritic control & $0.22 \pm 0.013$ & $0.20 \pm 0.016$ & $0.2 \pm 0.014$ & $0.13 \pm 0.012$ & $0.09 \pm 0.006$ \\
\hline Indomethacin $(10 \mathrm{mg} / \mathrm{kg})$ & $0.20 \pm 0.019$ & $0.23 \pm 0.015$ & $0.28 \pm 0.014 * *$ & $0.34 \pm 0.009 * * *$ & $0.41 \pm 0.008 * * *$ \\
\hline PLDE $(100 \mathrm{mg} / \mathrm{kg})$ & $0.22 \pm 0.016$ & $0.20 \pm 0.018$ & $0.22 \pm 0.015$ & $0.24 \pm 0.014 * * *$ & $0.30 \pm 0.007 * * *$ \\
\hline PHDE (200 mg/kg) & $0.24 \pm 0.019$ & $0.28 \pm 0.014 *$ & $0.31 \pm 0.010 * * *$ & $0.35 \pm 0.008 * * *$ & $0.39 \pm 0.007 * * *$ \\
\hline TLDE (100 mg/kg) & $0.23 \pm 0.027$ & $0.20 \pm 0.024$ & $0.168 \pm 0.022$ & $0.178 \pm 0.019$ & $0.218 \pm 0.020^{* * *}$ \\
\hline THDE (200 mg/kg) & $0.251 \pm 0.029$ & $0.215 \pm 0.027$ & $0.17 \pm 0.024$ & $0.185 \pm 0.022$ & $0.23 \pm 0.026 * * *$ \\
\hline
\end{tabular}

Results are expressed as mean $\pm \mathrm{sem},(\mathrm{n}=6)$, analysed by one way ANOVA followed by Dunnet's test. ${ }^{*} \mathrm{P}<0.05,{ }^{* *} \mathrm{p}<0.01,{ }^{* * *} \mathrm{p}<0.001$ when arthritic control compared with other treated groups.

Table 3: Effect of Costus speciosus Koen extract on average change in paw volume in (ml).

\begin{tabular}{|c|c|c|c|c|c|}
\hline \multirow[t]{2}{*}{ Treatment } & \multicolumn{5}{|c|}{ Average change in paw volume $(\mathrm{ml})$} \\
\hline & Day 1 & Day 7 & Day 14 & Day 21 & Day 28 \\
\hline Control (0.5 \% CMC) & $0.34 \pm 0.01$ & $0.42 \pm 0.05$ & $0.43 \pm 0.05$ & $0.43 \pm 0.06$ & $0.38 \pm 0.09$ \\
\hline Arthritic control & $2.92 \pm 0.17$ & $3.29 \pm 0.16$ & $3.25 \pm 0.07$ & $3.15 \pm 0.08$ & $3.16 \pm 0.10$ \\
\hline Indomethacin $(10 \mathrm{mg} / \mathrm{kg})$ & $2.93 \pm 0.15$ & $1.88 \pm 0.10^{* * *}$ & $1.57 \pm 0.09 * * *$ & $1.39 \pm 0.05 * * *$ & $1.3 \pm 0.04 * * *$ \\
\hline PLDE $\quad(100 \mathrm{mg} / \mathrm{kg})$ & $2.85 \pm 0.09$ & $2.8 \pm 0.10^{* *}$ & $2.78 \pm 0.12 * *$ & $2.63 \pm 0.11 * *$ & $2.23 \pm 0.09 * *$ \\
\hline PHDE $\quad(200 \mathrm{mg} / \mathrm{kg})$ & $2.68 \pm 0.03$ & $2.41 \pm 0.06 * * *$ & $1.98 \pm 0.04 * * *$ & $1.65 \pm 0.03 * * *$ & $1.31 \pm 0.03 * * *$ \\
\hline TLDE $\quad(100 \mathrm{mg} / \mathrm{kg})$ & $2.53 \pm 0.10^{*}$ & $2.98 \pm 0.04$ & $3.00 \pm 0.03$ & $2.78 \pm 0.03 *$ & $2.16 \pm 0.02 * *$ \\
\hline THDE $\quad(200 \mathrm{mg} / \mathrm{kg})$ & $2.58 \pm 0.10 * *$ & $2.93 \pm 0.07 *$ & $2.86 \pm 0.08 * *$ & $2.48 \pm 0.10 * *$ & $1.9 \pm 0.06^{* * *}$ \\
\hline
\end{tabular}

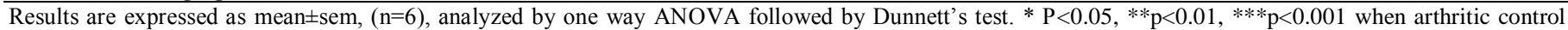
compared with other treated groups. 
Table 4: Effect of Costus speciosus Koen extract on average change in paw thickness (mm).

\begin{tabular}{|c|c|c|c|c|c|}
\hline \multirow[t]{2}{*}{ Treatment } & \multicolumn{5}{|c|}{ Average change in paw thickness $(\mathrm{mm})$} \\
\hline & Day 1 & Day 7 & Day 14 & Day 21 & Day 28 \\
\hline Control (0.5 \% CMC) & $4.16 \pm 0.03$ & $4.24 \pm 0.05$ & $4.24 \pm 0.06$ & $4.25 \pm 0.05$ & $4.21 \pm 0.05$ \\
\hline Arthritic control & $7.73 \pm 0.25$ & $8.06 \pm 0.12$ & $8.08 \pm 0.03$ & $8.02 \pm 0.04$ & $7.96 \pm 0.09$ \\
\hline Indomethacin $(10 \mathrm{mg} / \mathrm{kg})$ & $7.79 \pm 0.20$ & $5.93 \pm 0.16^{* * *}$ & $5.7 \pm 0.15^{* * *}$ & $5.44 \pm 0.14 * * *$ & $5.38 \pm 0.09 * * *$ \\
\hline PLDE (100 mg/kg) & $7.67 \pm 0.15$ & $7.61 \pm 0.14 *$ & $7.38 \pm 0.26^{* *}$ & $7.22 \pm 0.20 * *$ & $6.67 \pm 0.23 * * *$ \\
\hline PHDE (200 mg/kg) & $7.98 \pm 0.08$ & $7.27 \pm 0.09 * * *$ & $6.23 \pm 0.05^{* * *}$ & $5.98 \pm 0.02 * * *$ & $5.49 \pm 0.09 * * *$ \\
\hline TLDE (100 mg/kg) & $7.39 \pm 0.22$ & $7.87 \pm 0.12^{\mathrm{ns}}$ & $7.97 \pm 0.033^{\mathrm{ns}}$ & $7.49 \pm 0.12 *$ & $6.52 \pm 0.02 * * *$ \\
\hline THDE (200 mg/kg) & $7.22 \pm 0.22$ & $7.9 \pm 0.07^{\text {ns }}$ & $7.76 \pm 0.11^{\mathrm{ns}}$ & $7.1 \pm 0.21 * * *$ & $6.08 \pm 0.06^{* * *}$ \\
\hline
\end{tabular}

Results are expressed as mean \pm sem, $(\mathrm{n}=6)$, analysed by one way ANOVA followed by Dunnet's test. ${ }^{*} \mathrm{P}<0.05,{ }^{* *} \mathrm{p}<0.01,{ }^{* * *} \mathrm{p}<0.001$ when Arthritic control group compared with other treated groups.

Table 5: Effect of Costus speciosus Koen extract on body weight of animals.

\begin{tabular}{|c|c|c|c|c|c|c|}
\hline \multirow{2}{*}{ Treatment and dose } & \multicolumn{5}{|c|}{ Body weights } & \multirow{2}{*}{$\begin{array}{l}\text { \% change in body } \\
\text { weight }\end{array}$} \\
\hline & Day 0 & Day 7 & Day 14 & Day 21 & Day 28 & \\
\hline Control (0.5 \% CMC) & $211 \pm 15.85$ & $211.33 \pm 16.59$ & $212.16 \pm 14.56$ & $213.33 \pm 14.14$ & $214 \pm 13.95$ & $1.92 \pm 1.39 \uparrow$ \\
\hline Arthritic control & $191.16 \pm 6.52$ & $174.5 \pm 7.23$ & $170.33 \pm 5.74$ & $162.5 \pm 5.16$ & $154.33 \pm 4.65$ & $19.14 \pm 1.31 \downarrow$ \\
\hline Indomethacin $(0.3 \mathrm{mg} / \mathrm{kg})$ & $220.5 \pm 3.20$ & $209.16 \pm 3.38$ & $219.83 \pm 3.32$ & $233.66 \pm 3.34$ & $238.83 \pm 3.43$ & $8.29 \pm 0.39 \uparrow * * *$ \\
\hline Prophylactic low dose $(100 \mathrm{mg} / \mathrm{kg})$ & $137.5 \pm 2.813$ & $127.5 \pm 2.90$ & $133.83 \pm 2.89$ & $137.83 \pm 3.38$ & $139.66 \pm 3.26$ & $1.53 \pm 0.53 \uparrow * * *$ \\
\hline Prophylactic high dose $(200 \mathrm{mg} / \mathrm{kg})$ & $153.5 \pm 2.55$ & $147.33 \pm 2.56$ & $151.5 \pm 2.61$ & $155.66 \pm 2.96$ & $160 \pm 2.75$ & $4.23 \pm 0.55 \uparrow * * *$ \\
\hline Therapeutic low dose $(100 \mathrm{mg} / \mathrm{kg})$ & $121.16 \pm 5.52$ & $104.66 \pm 5.15$ & $90.33 \pm 5.19$ & $96.33 \pm 5.70$ & $105.5 \pm 6.46$ & $11.26 \pm 3.10 \downarrow$ \\
\hline Therapeutic high dose $(200 \mathrm{mg} / \mathrm{kg})$ & $129.83 \pm 1.57$ & $115.66 \pm 2.15$ & $105.66 \pm 2.85$ & $117.5 \pm 3.34$ & $125.66 \pm 2.72$ & $3.25 \pm 1.07 \downarrow$ \\
\hline
\end{tabular}

Table 6: Effects of Costus speciosus Koen extract Liver enzymes.

\begin{tabular}{|c|c|c|c|}
\hline \multirow[t]{2}{*}{ Treatment } & \multicolumn{3}{|c|}{ Liver enzymes } \\
\hline & SGPT (U/L) & SGOT (U/L) & $\operatorname{ALP}(\mathbf{U} / \mathbf{L})$ \\
\hline$\overline{\text { Control (0.5 \% CMC) }}$ & $49.09 \pm 0.76$ & $56.56 \pm 2.00$ & $131.70 \pm 1.20$ \\
\hline Arthritic control & $138.85 \pm 3.36$ & $143.16 \pm 2.35$ & $256.32 \pm 4.60$ \\
\hline Indomethacin $(10 \mathrm{mg} / \mathrm{kg})$ & $74.97 \pm 0.98 * * *$ & $77.63 \pm 0.80 * * *$ & $159.66 \pm 1.84 * * *$ \\
\hline PLDE $(100 \mathrm{mg} / \mathrm{kg})$ & $130.45 \pm 1.14 * *$ & $131.32 \pm 1.88 * *$ & $239.00 \pm 1.30 * * *$ \\
\hline PHDE $(200 \mathrm{mg} / \mathrm{kg})$ & $91.66 \pm 1.3^{* * *}$ & $93.63 \pm 3.75^{* * *}$ & $186.59 \pm 1.24 * * *$ \\
\hline TLDE (100 mg/kg) & $134.57 \pm 1.4$ & $139.66 \pm 0.91$ & $249.166 \pm 2.55$ \\
\hline THDE $(200 \mathrm{mg} / \mathrm{kg})$ & $112.94 \pm 1.10^{* * * *}$ & $119.53 \pm 3.09 * * *$ & $216.93 \pm 1.71^{* * * *}$ \\
\hline
\end{tabular}
Results are expressed as mean \pm sem, $(\mathrm{n}=6)$, analysed by one way ANOVA followed by Dunnet's test. ${ }^{*} \mathrm{P}<0.05,{ }^{* *} \mathrm{p}<0.01,{ }^{* * *} \mathrm{p}<0.001$ when Arthritic control group compared with other treated groups.

\section{Determination of liver enzyme}

Elevation of liver enzymes ALP, SGOT, SGPT generally occurs in arthritis. There were marked elevations of liver enzymes revealing the progression of disease in animals of arthritic group. In standard group (Indomethacin $10 \mathrm{mg} / \mathrm{kg} \mathrm{BW}$ ) and PHDE (200 $\mathrm{mg} / \mathrm{kg} \mathrm{BW}$ ) group there was significant decrease in level of these enzymes. In PLDE (100 mg/kg BW) and THDE (200 mg/kg) the decrease is less significant when compared to arthritic control. However, in TLDE $(100 \mathrm{mg} / \mathrm{kg} \mathrm{BW})$ there was no alteration in level of liver enzymes. Results are shown in table 6.

\section{Estimation of nitric oxide}

The changes in nitric oxide concentration assayed in serum of rats at $28^{\text {th }}$ day are presented in figure 1 . The result has shown that there is significant increase in level of nitric oxide in arthritic control group. It can easily be found out with help of figure that there is significant reduction in level of nitric oxide in standard indomethacin group, PHDE $(200 \mathrm{mg} / \mathrm{kg})$, PLDE (100 $\mathrm{mg} / \mathrm{kg}$ ), and THDE (200 mg/kg). However, the reduction of nitric oxide level in TLDE $(100 \mathrm{mg} / \mathrm{kg})$ is not significant.

\section{Estimation of plasma TNF- $\alpha$}

Figure 2 clearly indicate that high level of TNF- $\alpha$ were observed in arthritic control group rats. Indomethacin, PHDE
(200 mg/kg), PLDE (100 mg/kg) and THDE (200 mg/kg) reduced the level of plasma TNF- $\alpha$ significantly. However, the effect of TLDE $(100 \mathrm{mg} / \mathrm{kg})$ is not significant.

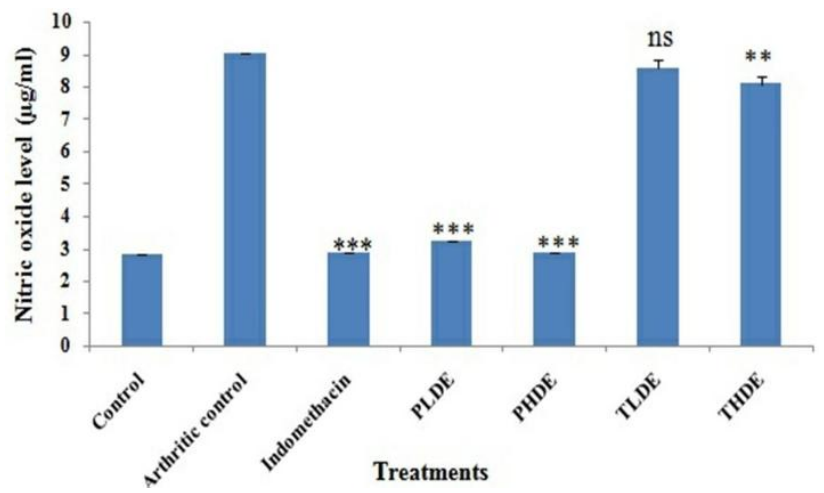

Fig. 1: Effect of Costus speciosus on Nitric oxide level $(\mu \mathrm{g} / \mathrm{ml})$ in treatment groups. Results are expressed as mean $\pm \operatorname{SEM},(n=6)$, analyzed by one way ANOVA followed by Dunnet's test. * $\mathrm{p}<0.05, * * \mathrm{p}<0.01, * * * \mathrm{p}<0.001$ when arthritic control compared with other treated.

\section{Radiological evaluation}

Radiological examination of tibio-tarsal joint was done.

It was seen that normal control group animals showed normal picture of joint. Animal in arthritic control group showed diffused joint and narrowing of the joint space. Animals in standard group 
(Indomethacin $(10 \mathrm{mg} / \mathrm{kg}))$ and other treatment group like PLDE (100 mg/kg), PHDE (200 mg/kg), and THDE (200 mg/kg) shows significant reduction in narrowing of joint space whereas, in TLDE (100 $\mathrm{mg} / \mathrm{kg}$ ) the effect was less significant in reduction in narrowing of joint space.

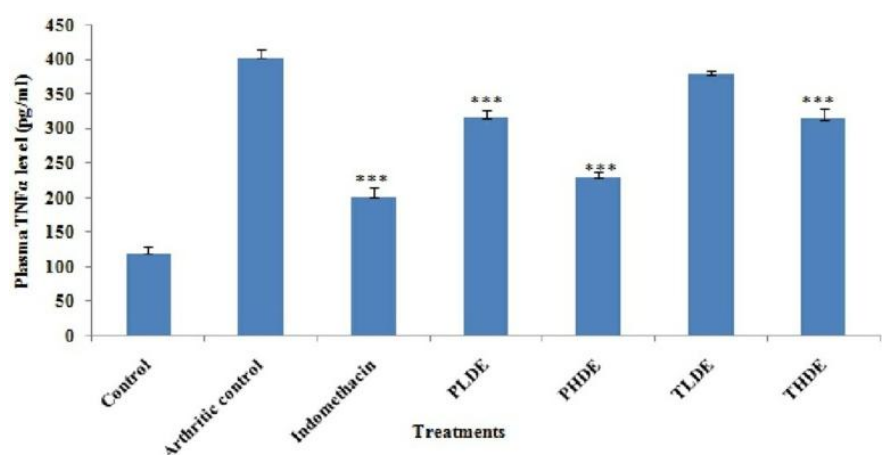

Fig 2: Effect of Costus speciosus on plasma TNF- $\alpha$ level $(\mathrm{pg} / \mathrm{ml})$ in treatment groups. Results are expressed as mean $\pm \operatorname{SEM},(\mathrm{n}=6)$, analyzed by one way ANOVA followed by Dunnet's test. ${ }^{*} \mathrm{p}<0.05,{ }^{* *} \mathrm{p}<0.01,{ }^{* * *} \mathrm{p}<0.001$ when arthritic control compared with other tre

\section{Histopathological assessment}

Histopathology study of tibio-tarsal joint was also done. In Normal control group, joint of animal showed normal cross section of joint. In Arthritic control group, joint of animal showed marked synoviocytes proliferation and inflammation with eosinophils and plasma cell. Joint of animal in PLDE $(100 \mathrm{mg} / \mathrm{kg})$ shows acute and chronic inflammation of joint space. Marked proliferation of synoviocytes. PHDE (200 mg/kg) joint showed normal minimal inflammation and reduced inflammatory mediator and less synoviocytes proliferation. In TLDE (100 mg/kg) crossection of complete joint shows marked synovial proliferation and sparse to moderate mixed amount of inflammatory infiltrate. In THDE (200 mg/kg) showed mild synovial proliferation. Inflammation is mostly chronic.

\section{DISCUSSION}

A small portion of methanolic extract was used for phytochemical evaluation which confirmed the presence of Flavonoids, phenolic compounds, steroidal compound, saponin and carbohydrates. It was found out in previous research that extracts of Costus speciosus in different polar solvents were rich in polyphenols(Nehete et al., 2010). Polyphenols reduces the chronic inflammation or its downstream consequences. They could reduce various pro-inflammatory substance productions through antioxidant effect (Ghiringhelli et al., 2012). The pro-inflammatory cytokines/chemokines such as TNF $\alpha$, IL-1 $\beta$, IL-6, IL- 8 are also reduced in many cell types. Reactive oxygen species are known plays an important role in development and maintenance of rheumatoid arthritis in human and animal models. Synoviocytes and chondrocytes produce nitric oxide which is responsible in production free radical giving rise to highly toxic radical peroxynitrite. The study of experimental animals has demonstrated increased activity of iNOS. Inhibition of NF- $\mathrm{BB}$ prevents reactive oxygen species by inhibition iNOS. Polyphenols inhibits NO release by suppressing NOS activity. Varieties of flavonoids suppress NO production and inhibition of NOS transcription, which occur by binding of NF- $\kappa \mathrm{B}$ to promoter of iNOS thereby in activating them (Santangelo et al., 2007, Cheeke et al., 2006). The presence of flavon-3-ols has been confirmed scientifically in Costus speciosus. Three of flavonoids such as quercitin and rutin and quercitrin were known to possess very high anti-oxidant activity (Chang et al., 2012). It has also been reported that two of the constituent of Costus speciosus, Costunolide and eremanthin could significantly reduced TBARS level and increase GSH level (Elisa et al., 2010). This anti-oxidant activity could also be the possible mechanism of anti-arthritic effect of Costus speciosus. It was reported in different research that rhizome of Costus speciosus possess anti-inflammatory, anti-oxidant, antipyretic, activities. So, the observed anti-arthritic activity of Costus speciosus is may be due to its anti-oxidant potential via different mechanisms. Based on these observations we reached to a conclusion that methanolic extract of Costus speciosus was found to be rich in flavonoid, phenolic compounds, carbohydrates and steroidal compounds. The presence of these compounds undertake role in antiarthritic activity of rhizome of Costus speciosus. The antiarthritic activity was demonstrated by measurement of arthritic score, arthritic index, paw thickness, inflammation, and pain. Measurement of liver enzymes ALP, SGOT, SGPT was also done because elevation of liver enzymes generally occurs in arthritis. There were marked reductions of liver enzymes indifferent treatment groups. Anti-arthritic effect attributable to anti-oxidant and antiinflammatory property was confirmed by marked reduction in nitric oxide level, plasma TNF- $\alpha$ level, Rheumatoid factor level and C-reactive protein level. Finally, radiological estimation and Histopathological estimation of tibio tarsal joint revealed the antiarthritic potential of methanolic extract of rhizome of Costus speciosus. Finally it can be concluded that, additional works on identification and isolation of active constituents in the extracts may be explored to determine the exact mechanism of the antiarthritic activity.

\section{CONCLUSION}

In conclusion, the extract is effective in reducing illeffects of RA both prophylactically and therapeutically. But, therapeutic low dose extract (TLDE $100 \mathrm{mg} / \mathrm{kg}$ ) does not show significant effect. While, PHDE (200 mg/kg), PLDE (100 mg/kg) and THDE $(200 \mathrm{mg} / \mathrm{kg})$ showed significant reduction in arthritic score, arthritic index, pain, edema and inflammation. They also, normalized the body weight of arthritic animal and reduced liver enzymes. From biochemical estimation like nitric oxide level and TNF- $\alpha$ level it was clear that these prophylactic and therapeutic doses are capable of reducing inflammatory mediators. Finally radiological and histopathological analysis supported the antiarthritic profile of Costus speciosus rhizome extract. Among all these treatment doses, PHDE $(200 \mathrm{mg} / \mathrm{kg})$ afforded maximum protection against FCA induced arthritis. 


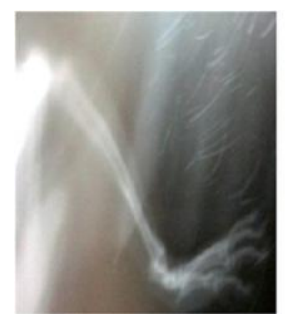

Control (0.5\% CMC)

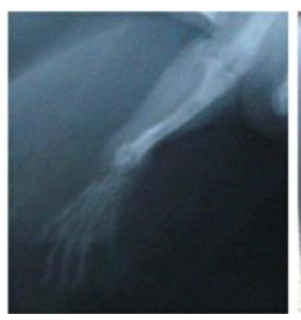

Arthritic Control

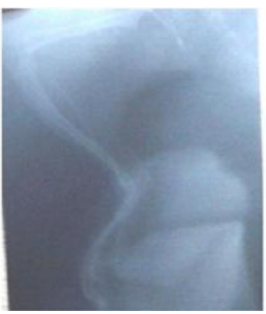

Indomethacin (10mg/Kg)

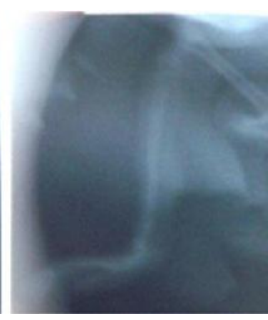

PLDE

(100mg/Kg)

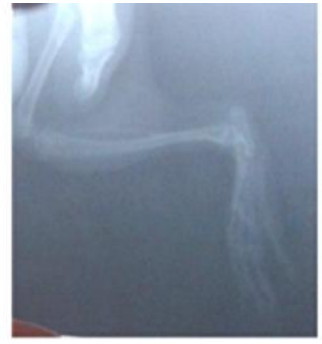

PHDE (200gm/kg)

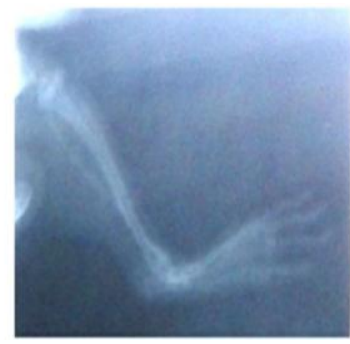

TLDE (100mg/kg)

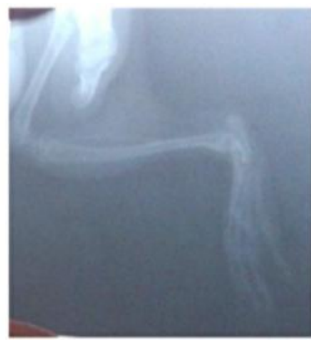

THDE (100mg/kg)

Fig. 3: Radiological examination of Tibio-tarsal joints of animals in different treatment groups.

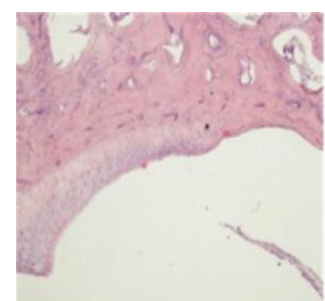

Control (0.5\% CMC)

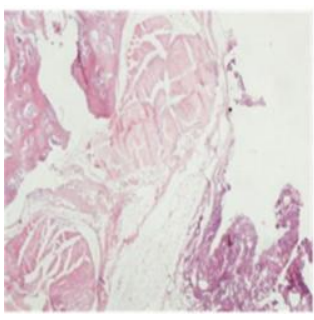

PHDE (20mg/Kg)

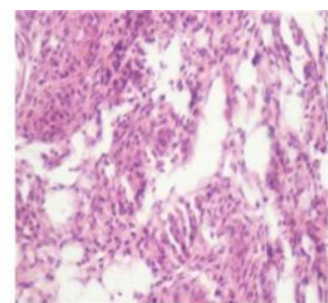

Arthritic Control

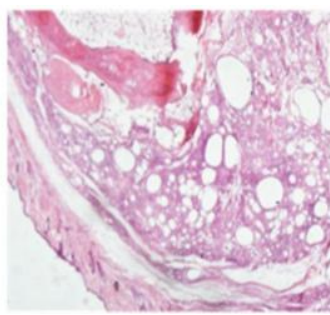

TLDE (100mg/Kg)

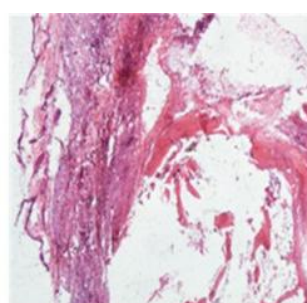

PLDE (100mg/Kg)

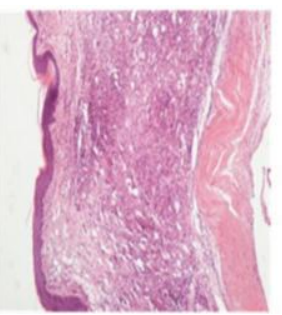

THDE (200mg/Kg)

Fig. 4: Histopathological study of tibio-tarsal joint of animals in different treatment groups.

\section{REFERENCES}

Al-Mailiki ADM. Isolation and identification of phenolic compounds from Elettaria cardamomum seeds and study of their medicinal activity against Pathogenic Bacteria of Prostate Gland. Journal of Misan Researches, 2011; 8(15): 13-35.

Anderson ML. Evaluation of acute and chronic treatments with Harpagophytum procumbens on Freund's adjuvant-induced arthritis in rats. J Ethnopharmacol, 2004; 91: 325-330.

Bhangle J, Acharya S. Antiarthritic activity of Cynodon dactylon (L.) Pers. Indian J Exp Biol, 2014; 52:215-222.

Boon NA, Colledge NR. 2006. Walker Brian. Davidson's principle and practice of medicine. 20th ed. Churchill livingtone: Elsevier.

Chang YQ, Tan SN, Yong JWH, Ge L. Determination of flavonoids in Costus speciosus and etlingera elatior by liquid chromatography-mass spectrometry. Analyt Lett, 2012; 45: 345-355.

Cheeke PR, Piacente S, Oleszek W. Anti-inflammatory and anti-arthritic effects of yucca schidigera: A Review. J Inflamm, 2006; 3(6):1-7
Elisa J, Daisy P, Ignacimuthu S. Antioxidant activity of costunolide and eremanthin isolated from Costus speciosus (Koen ex. Retz) Sm. Chem Biol Interact, 2010; 182(1):67-72

Gaspar MM. Enzymosomes with surface-exposed superoxide dismutase: In vivo behaviour and therapeutic activity in a model of adjuvant arthritis. J Control Release, 2007; 117:186-195.

Ghiringhelli F, Rebe C, Hichami A, Delmas D. Immunomodulation and anti-inflammatory roles of polyphenols as anticancer agents. Anticancer Agents Med Chem, 2012; 9(3): 852-73

Khandelwal KR. 2008. Practical Pharmacognosy. New Delhi: Pragati Books Pvt. Ltd

Menaka KB, Ramesh A, Thomas B, Kumari N.S. Estimation of nitric oxide as aninflammatory marker in periodontitis. JISP, 2009; 13(2).

Momin MAA, Bellah SF, Rahman SMR, Rahman AA, Murshid GMM, Emran TB. Phytopharmacological evaluation of ethanol extract of Sida cordifolia L. roots. Asian Pac J Trop Biomed, 2014; 4(1): 18-24.

Nehete J, Bhatia M, Narkhede M. In-vitro estimation of antioxidant activity and phenolic content of Costus speciosus (Koen) J.E. Sm. Iran J Pharm Res, 2010;9(3): 271-277. 
OECD guideline for the testing of chemicals. Acute oral toxicity-Up- and- down procedure (UDP). 2006; 4/26.

Orisatoki RO, Oguntibeju OO. The role of herbal medicine use in HIV/AIDS treatment. ACMicrob, 2010; 1(3.3).

Ramprasath VR. Curative effect of Semecarpus anacardium Linn. nut milk extract against adjuvant arthritis - with special reference to bone metabolism. Chem-Biol Interact, 2006; 160:183- 192.

Rani SA, Sulakshana G, Patnaik S. Costus speciosus, an antidiabetic plant - review. FS J Pharm Res, 2012; 1(3): 52-53.

Santangelo C, Vari R, Scazzocchio B, Benedetto RD, Filesi C, Masella R. Polyphenols, intracellular signaling and inflammation. Ann Ist Super Sanita, 2007; 43(4): 394-405.

Sehgal R, Kumar VL. Calotropis procera Latex-Induced Inflammatory Hyperalgesia-Effect of Anti-inflammatory Drugs. Mediators Inflamm, 2005; 4:216-220.

Srivastava S, Singh P, Mishra G, Jha KK, Khosa RL. Costus speciosus (Keukand): A review. Der Pharmacia Sinica, 2011;2(1):118-128
Srivastava S, Singh P, Mishra G, Jha KK, Srivastava S, Khosa RL. Evaluation of antiarthritic potential of methanolic extract aerial parts of Costus speciosus. J Ayurveda Integr Med, 2012; 3(4): 204208.

Trease GE, Evans WC. 2002. A Text book of Pharmacognosy. 15th ed. Harcourt brace \& Co. Asia, Pvt. Ltd: W.B. Saunders Company Ltd.

Vogel HG, Vogel, WH. 2010. Drug Discovery and Evaluation. Pharmacological Assay. Mass J. Springer.

\section{How to cite this article:}

Chandra Kala, Syed Salman Ali, Mohd Abid, Uma Shanker Sharma, Najam Ali Khan. Evaluation of in-vivo antiarthritic potential of methanolic extract of Costus speciosus rhizome. J App Pharm Sci, 2015; 5 (08): 046-053. 